\title{
A neutron track etch detector for electron linear accelerators in radiotherapy
}

\author{
Branko Vukovic ${ }^{1}$, Dario Faj², Marina Poje1, Maja Varga1, Vanja Radolic ${ }^{1}$, \\ Igor Miklavcic ${ }^{1}$, Ana Ivkovic ${ }^{2}$, Josip Planinic ${ }^{1}$ \\ ${ }^{1}$ Department of Physics, University of Osijek; Osijek, Croatia \\ ${ }^{2}$ Clinical Hospital Osijek, Osijek, Croatia
}

Received 16 September 2009

Accepted 16 November 2009

Correspondence to: Branko Vuković, PhD, Department of Physics, University of Osijek, P.O. Box 125, HR-31000 Osijek, Croatia. Phone: +385 31232 700; Fax: +385 31232 701. E-mail: branko@fizika.unios.hr

Disclosure: No potential conflicts of interest were disclosed.

\begin{abstract}
Background. Electron linear accelerators in medical radiotherapy have replaced cobalt and caesium sources of radiation. However, medical accelerators with photon energies over $10 \mathrm{MeV}$ generate undesired fast neutron contamination in a therapeutic X-ray photon beam. Photons with energies above $10 \mathrm{MeV}$ can interact with the atomic nucleus of a high-Z material, of which the target and the head of an accelerator consist, and lead to the neutron ejection. Results and conclusions. Our neutron dosimeter, composed of the LR-115 track etch detector and boron foil $\mathrm{BN}-1$ converter, was calibrated on thermal neutrons generated in the nuclear reactor of the Josef Stefan Institute (Slovenia), and applied to dosimetry of undesirable neutrons in photon radiotherapy by the linear accelerator 15 MV Siemens Mevatron. Having considered a high dependence of a cross-section between neutron and boron on neutron energy, and broad neutron spectrum in a photon beam, as well as outside the entrance door to maze of the Mevatron, we developed a method for determining the effective neutron detector response. A neutron dose rate in the photon beam was measured to be $1.96 \mathrm{~Sv} / \mathrm{h}$. Outside the Mevatron room the neutron dose rate was $0.62 \mu \mathrm{Sv} / \mathrm{h}$. PACS: 87.52. Ga; 87.53.St; 29.40.Wk.
\end{abstract}

Key words: electron linear accelerator; photoneutron; track etch detector; neutron dose equivalent

\section{Introduction}

Nowadays, cobalt and caesium teletherapy machines in medical radiotherapy are being replaced by linear accelerators. ${ }^{1}$ The great advantage of this new equipment is that it has no attached radioactive source, which makes them safer from the radiological point of view. However, medical accelerators with photon energies over $10 \mathrm{MeV}$ generate undesired fast neutron contamination in a therapeutic beam. Photons with energies above $10 \mathrm{MeV}$ can interact with the atomic nucleus of a high- $\mathrm{Z}$ material, of which the target and the head of the accelerator consist, and lead to the neutron ejection. Consequently, this can increase the patient dose and pose a problem in room shielding dosimetry, which is essential for the quality assurance in radiotherapy. ${ }^{2,3}$

Neutrons are principally produced through giant dipole resonance in a nuclear reaction $(\gamma, \mathrm{n})$ between photons and target nuclei. ${ }^{4}$ The giant resonance process produces two groups of neutrons; the first and the largest group has a spectrum, which can be described by a Maxwellian distribution, with the most probable energy, typically between 0.4 and 1 $\mathrm{MeV}$; the second group of neutrons is produced by direct emission and is somewhat higher in energy (up to $10-20 \%$ of the total neutrons in general). ${ }^{5}$ The mean energy of the neutron spectrum generated by the $(\gamma, \mathrm{n})$ reaction is around a few $\mathrm{MeV}$, but, at the patient plane, neutrons have a more complex distribution and a less mean energy. As beam energies increase $(>10 \mathrm{MeV})$, an undesirable photoneutron dose also increases. Otherwise one can expect, that inside the area treated by linear accelerator, the neutron dose in a tissue will not exceed $1 \%$ of the photon dose. ${ }^{6}$

\section{Material and methods}

The neutron dosimeter consisted of the LR-115 track detector and boron foil BN-1 (Kodak-Pathe, 
France) or ${ }^{10} \mathrm{~B}$ converter for reaction $(\mathrm{n}, \alpha)$; it was calibrated on neutrons generated in the nuclear reactor of the J. Stefan Institute (Slovenia). ${ }^{7}$ Neutron irradiation was carried out in the thermal column of the TRIGA Mark II reactor where the neutron flux was $\Phi=3.33 \times 10^{5} \mathrm{~cm}^{-2} \mathrm{~s}^{-1}$; for irradiation time, $\mathrm{t}=240 \mathrm{~s}$, we got the fluence, $\mathrm{f}=\Phi \mathrm{t}=7.99 \times 10^{7} \mathrm{~cm}^{-2}$.

The LR-115 detectors, $2 \times 3 \mathrm{~cm}^{2}$, were etched in a $10 \% \mathrm{NaOH}$ aqueous solution at $60{ }^{\circ} \mathrm{C}$ for $120 \mathrm{~min}$ and afterwards counted visually using a microscope of (10x16) magnification.

The irradiated neutron track etch detector had a net track density $D_{\mathrm{t}}=(63394-\mathrm{B}) \cong 63370 \mathrm{~cm}^{-2}$, where the background, $\mathrm{B}$, was $24 \mathrm{~cm}^{-2}$; the standard deviation of the $D_{t}$ was $s_{D t}=570$. The response, $r_{t^{\prime}}$ of the neutron dosimeter for thermal neutrons was:

$$
\mathrm{r}_{\mathrm{t}}=\mathrm{D}_{\mathrm{t}} / \mathrm{f}=(7.930 \pm 0.071) \times 10^{-4},
$$

where the error was given as a standard deviation, $\mathrm{s}_{\mathrm{rt}}=\mathrm{s}_{\mathrm{Dt}} / \mathrm{f}=7.1 \times 10^{-6}$.

The electron linear accelerator Siemens Mevatron $15 \mathrm{MV}$ has been used as an X-ray radiotherapy source in the Clinical Hospital Osijek. The same accelerator was used to perform experiments for determining a dose equivalent of undesirable photoneutrons by using the neutron track etch detector.

\section{Results and discussion}

\section{Linear accelerator neutrons - track detector in the beam}

In order to determine a dose equivalent of photoneutrons produced by linear accelerator, operating in a photon production mode at an acceleration potential of $15 \mathrm{MV}$, we used the LR-114 track etch detector, which was positioned in the beam at $1 \mathrm{~m}$ from the accelerator head.

For fast neutrons with higher energy, a detector response should be lower; having considered a total cross-section of neutrons on boron, ${ }^{10} \mathrm{~B}(\mathrm{n}, \alpha)^{7} \mathrm{Li}$, depending on neutron energy $(\sigma(\mathrm{E}) \text {, Figure } 1)^{8}$, as well as a neutron fluence spectrum on energies by the linear accelerator (Figure 2) ${ }^{2}$, we divided neutron energy $\mathrm{E}_{\mathrm{a}}(\mathrm{MeV})$ in the two areas as follows: the first area , $0<\mathrm{E}_{\mathrm{a} 1}<0.5$, and the second one, 0.5 $\leq \mathrm{E}_{\mathrm{a} 2} \leq 7.5$.

Afterwards, we estimated the respective mean cross-sections $\sigma_{\mathrm{t}}=1000 \mathrm{~b}$ (for thermal neutrons), $\sigma_{\mathrm{a} 1}$ $=1.33 \mathrm{~b}$ and $\sigma_{\mathrm{a} 2}=0.25 \mathrm{~b}$ (for energies $\mathrm{E}_{\mathrm{a} 1}$ and $\mathrm{E}_{\mathrm{a} 2}$ respectively) from the curve $\sigma(\mathrm{E})$ in Figure 1 , and

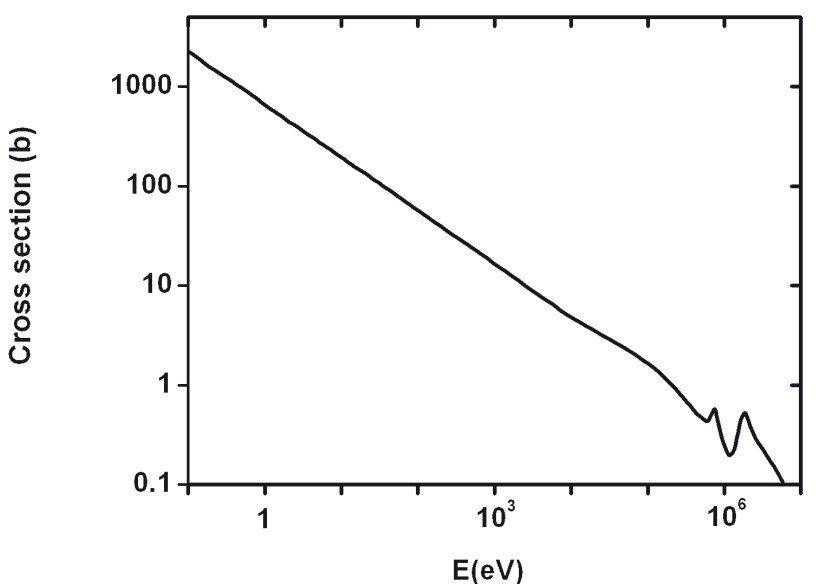

FIGURE 1. The total cross-sections of neutrons on boron $(\sigma / b)$ versus neutron energy $(\mathrm{E} / \mathrm{eV}) .^{8}$

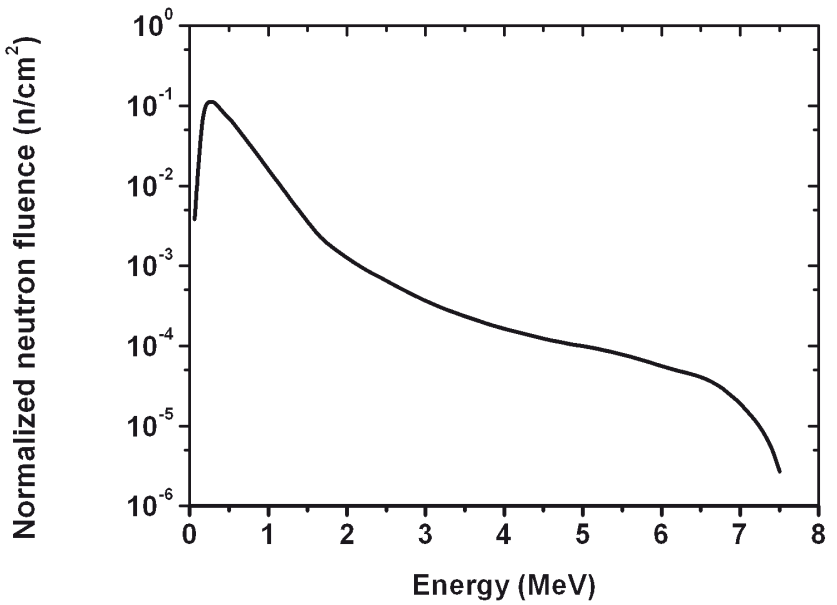

FIGURE 2. Neutron spectrum produced in $15 \mathrm{MV}$ linear accelerator after crossing the tungsten head; fluence $\left(\mathrm{f} / \mathrm{n} \mathrm{cm}^{-2}\right)$ versus neutron energy $(\mathrm{E} / \mathrm{MeV}) .^{2}$

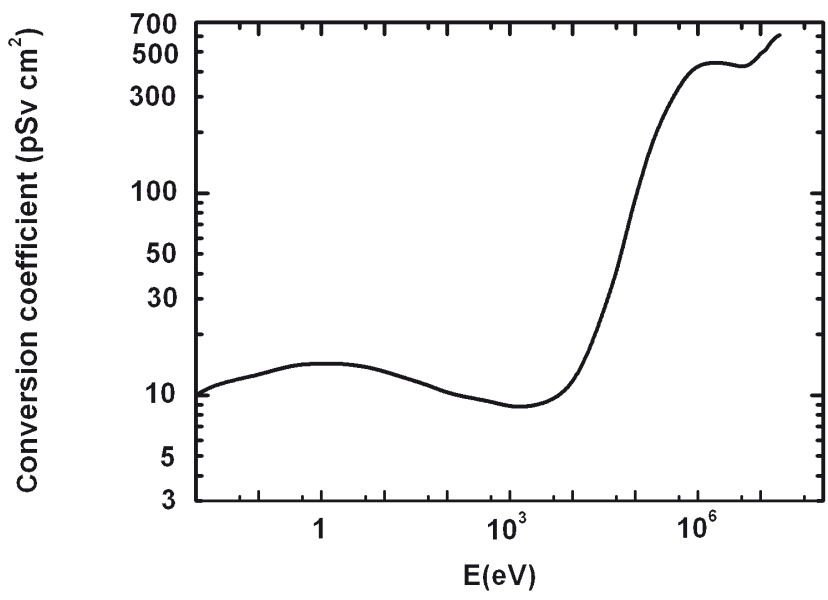

FIGURE 3. Conversion coefficient $\left(\mathrm{k} / \mathrm{pS} v \mathrm{~cm}^{2}\right)$ from neutron fluence to personal dose equivalent versus neutron energy $(\mathrm{E} / \mathrm{eV})$. 
we determined the neutron detector responses for the tow energy areas as follows: $\sigma_{\mathrm{t}} / \sigma_{\mathrm{a} 1}=\mathrm{r}_{\mathrm{t}} / \mathrm{r}_{\mathrm{a} 1}, \sigma_{\mathrm{t}} / \sigma_{\mathrm{a} 2}$ $=r_{t} / r_{a 2}$, where the $r_{t}$ was the response that had already been calculated by using equation [1]. Thus we got $r_{a 1}=1.06 \times 10^{-6}$ and $r_{a 2}=2.00 \times 10^{-7}$, with the standard deviations of $9.1 \times 10^{-9}$ and $1.8 \times 10^{-9}$, respectively, and we were able to determine an average or effective value of the neutron detector response $\mathrm{r}_{\mathrm{ae}}$ but as a weighted or pondered mean. ${ }^{9}$

Therefore, we took the surfaces under the neutron fluence spectrum curve (Figure 2; $\mathrm{f}(\mathrm{E})$ ) for the two energy areas as above and we got the relative surfaces: $\mathrm{s}_{\mathrm{a} 1}=0.58$ and $\mathrm{s}_{\mathrm{a} 2}=0.42$, those had the meaning of the relative frequencies in the calculation of the pondered mean (for instance, $\mathrm{s}_{1}$ is the ratio of the surface under the curve between 0 and 0.5 $\mathrm{MeV}$ to the total surface under the curve between 0 and $7.5 \mathrm{MeV}$ ). The mean or effective detector response was: $\mathrm{r}_{\mathrm{ae}}=\mathrm{r}_{\mathrm{a} 1} \mathrm{~s}_{\mathrm{a} 1}+\mathrm{r}_{\mathrm{a} 2} \mathrm{~s}_{\mathrm{a} 2}=(6.97 \pm 0.07) \times 10^{-7}$.

For a measured detector density $\mathrm{D}_{\mathrm{a}^{\prime}}$, the respective fluence was (like in equation [1]): $\mathrm{f}_{\mathrm{ae}}=\mathrm{D}_{\mathrm{a}} / \mathrm{r}_{\mathrm{ae}}$. When the neutron fluence is known, a conversion coefficient $(k)$ from neutron fluence to dose equivalent, depending on neutron energy, gives a personal dose equivalent $\left(\mathrm{H}_{\mathrm{a}}\right)$, as follows: ${ }^{10} \mathrm{H}_{\mathrm{a}}=\mathrm{k}_{\mathrm{ae}} \mathrm{f}_{\mathrm{ae}}$.

Having considered a great dependence of $k$ on neutron energy (Figure 3), we calculated the average or effective $k_{\mathrm{ae}}$ for the two energy areas, like above, and we used the same relative frequencies $\mathrm{s}_{\mathrm{ai}}(\mathrm{i}=1,2)$; taking the average values of $k_{\mathrm{a}}$ for the neutron energies $E_{a 1}$ and $E_{a 2}$ as $k_{a 1}=200$ and $k_{a 2}=$ $430 \mathrm{pSv} \mathrm{cm}{ }^{2}$, respectively, we calculated the effective conversion factor as follows:

$$
\mathrm{k}_{\mathrm{ae}}=\mathrm{k}_{\mathrm{a} 1} \mathrm{~S}_{\mathrm{a} 1}+\mathrm{k}_{\mathrm{a} 2} \mathrm{~S}_{\mathrm{a} 2}=296.4 \mathrm{pSv} \mathrm{cm}{ }^{2} .
$$

Thus, the measured detector net density $\mathrm{D}_{\mathrm{a}}=$ (383.1 \pm 0.04$) \mathrm{cm}^{-2}$ corresponded to the following dose equivalent:

$$
\begin{aligned}
& \mathrm{H}_{\mathrm{a}}=\mathrm{k}_{\mathrm{ae}} \mathrm{f}_{\mathrm{ae}}=\mathrm{k}_{\mathrm{ae}} / \mathrm{r}_{\mathrm{ae}} \mathrm{D}_{\mathrm{a}}=425.5 \mathrm{D}_{\mathrm{a}}(\mu \mathrm{Sv}), \\
& \mathrm{H}_{\mathrm{a}}=(0.163 \pm 0.002) \mathrm{Sv}
\end{aligned}
$$

The dose rate was calculated as a ratio of the dose equivalent and exposure time, $t$, or:

$\dot{H}=\mathrm{H} / \mathrm{t}$, and for $\mathrm{t}=5 \mathrm{~min}$, we got the dose rate $\dot{H}=(1.96 \pm 0.02) \mathrm{Sv} / \mathrm{h}$.

The measurement errors were determined as variances or standard deviations for track densities in the following way (according to the Poisson distribution):

$$
\mathrm{S}_{\mathrm{D}}^{2}=\mathrm{S}_{\mathrm{Db}}^{2}+\mathrm{S}_{\mathrm{B}}^{2}=\mathrm{D}_{\mathrm{b}}+\mathrm{B} \text {; }
$$

The dose equivalent variance was calculated as total differential of the function of the form like in equitation [2], which led to the following expression:

$$
\mathrm{S}_{\mathrm{H}}^{2}=\left(\mathrm{kD} / \mathrm{r}^{2}\right)^{2} \mathrm{~S}_{\mathrm{r}}^{2}+(\mathrm{k} / \mathrm{r})^{2} \mathrm{~s}_{\mathrm{D}}^{2} .
$$

\section{Linear accelerator neutrons - track detector behind the wall}

The neutron track etch detector was positioned outside the entrance door to the accelerator maze. The neutron spectrum in the same position was measured by Schraube et al. ${ }^{11}$, hereby presented in Figure 4. We used the given neutron spectrum in the procedure for determining a neutron dose equivalent by the track detector, as above. Otherwise, neutron spectrum can vary depending on the wall construction of a room.

We divided neutron energy, $\mathrm{E}_{\mathrm{b}}$, in two areas as follows: the first area, $0<\mathrm{E}_{\mathrm{b} 1}<100 \mathrm{eV}$, and the second one, $100 \mathrm{eV} \leq \mathrm{E}_{\mathrm{b} 2} \leq 3750 \mathrm{eV}$. Because the $\mathrm{E}_{\mathrm{b} 1}$ was the area of thermal neutrons, we estimated the respective mean cross-sections $\sigma_{\mathrm{t}}=\sigma_{\mathrm{b} 1}=120 \mathrm{~b}$ and $\sigma_{b 2}=14.75 b$ (for energies $E_{b 1}$ and $E_{b 2}$, respectively) from the curve $\sigma(\mathrm{E})$ in Figure 1, and we determined the neutron detector responses for the low energy areas as follows: $\sigma_{b 1} / \sigma_{b 2}=r_{b 1} / r_{b 2}$, where $r_{b 1}=r_{t}$ was already assessed response by using equation [1]. Thus we got $\mathrm{r}_{\mathrm{b} 1}=7.94 \times 10^{-4}$ and $\mathrm{r}_{\mathrm{b} 2}=9.75 \times 10^{-5}$, and were able to determine the average or effective value of the neutron detector response $r_{b e}$ for neutrons in the energy area $E_{b}$.

As in the previous case, we took the surfaces under the neutron fluence spectrum curve (Figure 4; $f(E))$ for the two energy areas and we got the relative surfaces: $\mathrm{s}_{\mathrm{b} 1}=0.18$ and $\mathrm{s}_{\mathrm{b} 2}=0.82$, those had the meaning of the relative frequencies in the calculation of the pondered mean. The mean or effective detector response was: $\mathrm{r}_{\mathrm{be}}=\mathrm{r}_{\mathrm{b} 1} \mathrm{~s}_{\mathrm{b} 1}+\mathrm{r}_{\mathrm{b} 2} \mathrm{~s}_{\mathrm{b} 2}=2.2 \times 10^{-4}$.

For the measured detector density $D_{b}$, the respective fluence is (like in equation [1]): $\mathrm{f}_{\mathrm{be}}=\mathrm{D}_{\mathrm{b}} / \mathrm{r}_{\mathrm{be}}$. When the neutron fluence is known, a conversion coefficient $(k)$ from neutron fluence to dose equivalent, depending on neutron energy, gives a personal dose equivalent $\left(\mathrm{H}_{\mathrm{a}}\right)$, as follows: $\mathrm{H}_{\mathrm{b}}=\mathrm{k}_{\mathrm{be}} \mathrm{f}_{\mathrm{be}}$

Having considered a great depending $k$ on neutron energy (Figure 3), we calculated the average or effective $k_{b e}$ for the two energy regions, like above, and we used the same relative frequencies $\mathrm{s}_{\mathrm{bi}}(\mathrm{i}=1$, 2); taking the average values of $k_{\mathrm{b}}$ for the neutron energies $E_{b 1}$ and $E_{b 2}$ as $k_{b 1}=11.58$ and $k_{b 2}=9 p S v$ 
$\mathrm{cm}^{2}$, respectively, we calculated the effective conversion factor as follows:

$$
\mathrm{k}_{\mathrm{be}}=\mathrm{k}_{\mathrm{b} 1} \mathrm{~s}_{\mathrm{b} 1}+\mathrm{k}_{\mathrm{b} 2} \mathrm{~s}_{\mathrm{b} 2}=9.45 \mathrm{pSv} \mathrm{cm}{ }^{2} .
$$

Thus, the measured detector net density $\mathrm{D}_{\mathrm{b}}=$ $1.2 \pm 0.01 \mathrm{~cm}^{-2}$ corresponded to the following dose equivalent:

$$
\begin{aligned}
& \mathrm{H}_{\mathrm{b}}=\mathrm{k}_{\mathrm{be}} \mathrm{f}_{\mathrm{be}}=\mathrm{k}_{\mathrm{be}} / \mathrm{r}_{\mathrm{be}} \mathrm{D}_{\mathrm{b}}=42.9 \times 10^{-3} \mathrm{D}_{\mathrm{b}}(\mu \mathrm{Sv}), \\
& \mathrm{H}_{\mathrm{b}}=(0.050 \pm 0.0006) \mu \mathrm{Sv} .
\end{aligned}
$$

The dose rate was calculated as a ratio of the dose equivalent and exposure time of $5 \mathrm{~min}$, and we got the neutron dose rate outside the entrance door to the maze of the $15 \mathrm{MV}$ Mevatron, $\dot{H}_{b}=(0.62 \pm 0.007)$ $\mu \mathrm{Sv} / \mathrm{h}$. The linac room $1.7 \mathrm{~m}$ walls were constructed of barite concrete, with density of $3200 \mathrm{~kg} / \mathrm{m}^{3}$.

Although the obtained neutron dose rate outside the accelerator room was 3165 times smaller than the neutron dose rate in the photon beam, the measured dose rate $\dot{H}_{b}$ was not negligible from the aspect of personal dosimetry.

Some considerations of neutron energy attenuation after crossing the treatment room walls were performed for different concrete barrier thickness and materials. A neutron spectrum attenuation from the $15 \mathrm{MV}$ linear accelerator, after passing a conventional $1 \mathrm{~m}$ concrete barrier, with density of $2260 \mathrm{~kg} / \mathrm{m}^{3}$, was measured by Facure et al., hereby presented in Figure 5. ${ }^{2}$

Observing the neutron spectra in Figure 5 and Figure 4, one can notice a broad neutron energy area in Figure 5 (from $0.1 \mathrm{eV}$ to $10 \mathrm{MeV}$ ), that contributes to the neutron dose outside the Mevatron treatment room; neutrons that crossed the $1 \mathrm{~m}$ concrete barrier had higher energies than those behind the $1.7 \mathrm{~m}$ concrete wall (with energy below $1 \mathrm{keV}$ ).

In order to compare the neutron detection parameters $r_{e}$ and $k_{e^{\prime}}$ we divided neutron energy $E_{c}$ $(\mathrm{MeV})$ of the spectrum (Figure 5) in the two areas as follows: first area $\mathrm{E}_{\mathrm{c1}}<2 \mathrm{MeV}$, and the second one $2 \mathrm{MeV} \leq \mathrm{E}_{\mathrm{c} 2} \leq 7.5 \mathrm{MeV}$.

Afterwards, we estimated the respective mean cross-sections $\sigma_{\mathrm{t}}=\sigma_{\mathrm{c} 1}=0.619 \mathrm{~b}$ (for thermal neutrons, like above), $\sigma_{\mathrm{c} 2}=0.203 \mathrm{~b}$ (for energies $\mathrm{E}_{\mathrm{c} 1}$, $\mathrm{E}_{\mathrm{c} 2}$, respectively) from the curve $\sigma(\mathrm{E})$ in Figure1, and we determined the neutron detector responses for the three energy areas as follows: $\sigma_{\mathrm{c} 1} / \sigma_{\mathrm{c} 2}=\mathrm{r}_{\mathrm{c} 1} /$ $r_{c 2}$, where $r_{c 1}=r_{t}=7.94 \times 10^{-4}$ was the response that had already been calculated by using the equation [1]. Thus we got $r_{\mathrm{c} 2}=2.6 \times 10^{-4}$ and we were able

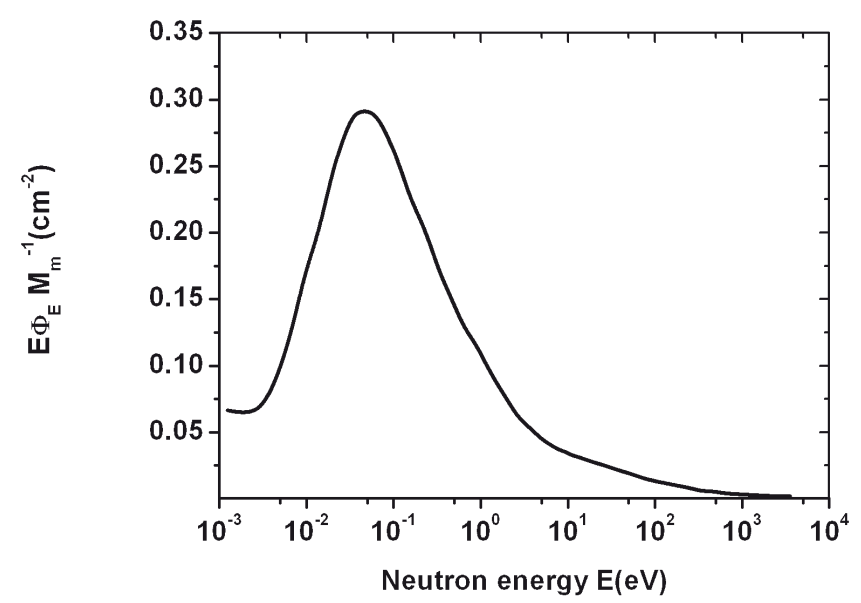

FIGURE 4. Neutron spectrum measured at position outside the entrance door to the maze of the 15 MV Mevatron. ${ }^{11}$

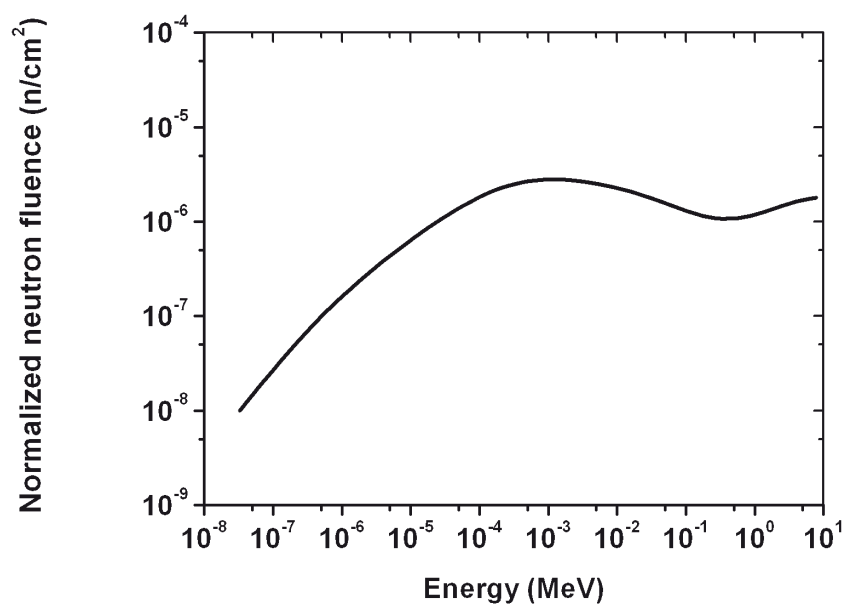

FIGURE 5. Neutron spectrum attenuation from a $15 \mathrm{MV}$ linear accelerator, after concrete barrier of $1 \mathrm{~m}$.

to determine the average or effective value of the neutron detector response $r_{\text {cé }^{\prime}}$ but as a weighted or pondered mean.

Therefore, we took the surfaces under the neutron fluence spectrum curve (Figure $5 ; \mathrm{f}(\mathrm{E})$ ) for the two energy regions, like above, and we got the relative surfaces: $\mathrm{s}_{\mathrm{c} 1}=0.22, \mathrm{~s}_{\mathrm{c} 2}=0.78$, which had the meaning of the relative frequencies in the calculation of the pondered mean. The mean or effective detector response was: $\mathrm{r}_{\mathrm{ce}}=\mathrm{r}_{\mathrm{c} 1} \mathrm{~s}_{\mathrm{c} 1}+\mathrm{r}_{\mathrm{c} 2} \mathrm{~s}_{\mathrm{c} 2}=(3.78 \pm$ 0.03) $\times 10^{-4}$.

Having considered a great depending $k$ on neutron energy (Figure 3), we calculated the average or effective $k_{\text {ce }}$ for the three energy areas, and we used the same relative frequencies $\mathrm{s}_{\mathrm{ci}}(\mathrm{i}=1,2,3)$; taking the average values of $k_{\mathrm{c}}$ for the neutron energies $\mathrm{E}_{\mathrm{c} 1}$ and $\mathrm{E}_{\mathrm{c} 2}$ as $\mathrm{k}_{\mathrm{c} 1}=366, \mathrm{k}_{\mathrm{c} 2}=433 \mathrm{pSv} \mathrm{\textrm {cm } ^ { 2 }}$, respectively, 
we calculated the effective conversion factor as follows:

$$
\mathrm{k}_{\mathrm{ce}}=\mathrm{k}_{\mathrm{c} 1} \mathrm{~s}_{\mathrm{c} 1}+\mathrm{k}_{\mathrm{c} 2} \mathrm{~s}_{\mathrm{c} 2}=418 \mathrm{pSv} \mathrm{cm}{ }^{2} \text {. }
$$

Thus, since $\mathrm{k}_{\mathrm{c}} / \mathrm{r}_{\mathrm{c}}=25,75 \mathrm{k}_{\mathrm{b}} / \mathrm{r}_{\mathrm{b}}$, and according to equation [2], one can see that neutrons of the given distribution in Figure 5 (behind the $1 \mathrm{~m}$ concrete barrier) contribute to a neutron dose 26 times more than neutrons from the distribution in Figure 4 (behind the $1.7 \mathrm{~m}$ concrete wall).

\section{Conclusions}

The neutron dosimeter, consisting of the LR-115 track etch detector and boron foil BN-1, was calibrated on thermal neutrons generated in the nuclear reactor of the J. Stefan Institute (Slovenia), and was applied to dosimetry of undesirable neutrons in photon radiotherapy with the Siemens Mevatron $15 \mathrm{MV}$ electron linear accelerator.

Having considered a broad neutron spectrum of energies in the photon beam and high dependence of the track detector response on neutron energy, we divided the spectrum in the two energy areas, below and over $2 \mathrm{MeV}$. Afterwards we determined the detector responses ( $r$ ) for the energy areas using corresponding cross-sections for neutron and boron, and then we calculated the pondered or effective response depending on surfaces under the respective neutron spectrum areas. Using the empirical curve $\mathrm{k}(\mathrm{E})$, we performed the similar procedure for determining an effective conversion coefficient $(k)$ from neutron fluence to dose equivalent, depending on neutron energy (E).

The relative measurement errors made by track etching method with the LR-115 detector were about $1 \%$. It is to mention that we took the data from the empirical curves (e.g. $\sigma(\mathrm{E}), \mathrm{k}(\mathrm{E}))$ as average values without respective experimental errors.

The measurement of the neutron dose equivalent by the track etch detector, positioned outside the Siemens Mevatron $15 \mathrm{MV}$ room (room wall of $1.7 \mathrm{~m}$, density of $3200 \mathrm{~kg} / \mathrm{m}^{3}$ ), gave the dose rate of $0.62 \mu \mathrm{Sv} / \mathrm{h}$.

Observing the neutron spectrum attenuation from 15 MV Mevatron behind the $1 \mathrm{~m}$ concrete barrier, one was able to notice that the neutrons (Figure 5) had higher energies and contributed to a neutron dose 26 factor times more than neutrons from the distribution in Figure 4 (behind the 1.7 concrete wall).

\section{References}

1. Strojnik A. In search of the shortest regimen: fractionation of a fully isoeffective combination of hyperfractionated and hypofractionated treatment. Radiol Oncol 2008; 42: 170-2.

2. Facure A, Falcão RC, Silva AX, Crispim VR, Vitorelli JC. A study of neutron spectra from medical linear accelerators. Appl Radiat Isotop 2005; 62: 6972.

3. D Ryan C Rivest, Terence A Riauka, Albert D Murtha, B Gino Fallone. Dosimetric implications of two registration based patient positioning methods 203 in prostate image guided radiation therapy (IGRT). Radiol Oncol 2009; 43: 203-12.

4. Ongaro C, Zanini A, Nastasi U, Rodenas J, Ottaviano G, Manfredotti C. Analysis of photoneutron spectra produced in medical accelerators. Phys Med Biol 2005; 45: 55-61.

5. Králík M, Turek K. Characterisation of neutron fields around high-energy $x$-ray radiotherapy. Radiat Prot Dosimetry 2004; 110: 503-7.

6. Rivera JC, Falcão RC, deAlmeida CE. The measurement of photoneutron dose in the vicinity of clinical linear accelerators. Radiat Prot Dosimetry 2008; 130: 403-9.

7. Izerrouken $\mathrm{M}$, Skvarč J, Ilić R. A wide range personnel neutron dosimeter. Radiat Meas 2003; 37: 21-4.

8. Lilley J. Nuclear Physics. Chichester: John Wiley \& Sons; 2001. p. 196.

9. Vuković B, Radolić V, Lisjak I, Vekić B, Poje M, Planinić J. Some cosmic radiation dose measurements aboard flights connecting Zagreb Airport. Appl Radiat Isotop 2008; 66: 247-51.

10. Lopez Ponte MA, Castellani CM, Currivan L, et al. A catalogue of dosimeters and dosimetric services within Europe-an update. Radiat Protec Dosim 2004; 112: 45-68.

11. Schraube $H$, Kneschaurek $P$, Schraube $G$, Wagner FM, Weitzenegger $E$. Neutron spectra around medical treatment facilities. Nucl Instrum Meth $A$ 2002; 476: 463-7. 